\title{
Cytotoxic, antiangiogenic and antitelomerase activity of glucosyl- and acyl- resveratrol prodrugs and resveratrol sulphate metabolites.
}

Eva Falomir ${ }^{1}$, Rosa Martí-Centelles ${ }^{1}$, Ricardo Lucas ${ }^{2}$, Alexia Dupont ${ }^{2}$, Miguel Carda ${ }^{1}$, Juan C. Morales ${ }^{2 *}$

${ }^{1}$ Department of Inorganic and Organic Chemistry, University Jaume I, 12071 Castellón, Spain. ${ }^{2}$ Department of Bioorganic Chemistry, Instituto de Investigaciones Químicas (IIQ), CSIC-Universidad de Sevilla, 41092 Sevilla, Spain.

Running Title: Cytotoxicity of resveratrol prodrugs and resveratrol metabolites.

*To whom correspondence should be addressed: M.C. (E-mail: mcarda@qio.uji.es) or J.C.M. (E-mail: jcmorales@iiq.csic.es).

Keywords: resveratrol, polyphenol, prodrug, metabolite, sulfate, cytotoxicity, antiproliferation, angiogenesis

Abbreviations: anh., anhydrous, $t-\mathrm{BuOH}$, tert-butanol, $\mathrm{C}_{\max }$, maximum concentration; $\mathrm{DCM}$, dichloromethane; DMF, dimethylformamide; $\mathrm{MeOH}$, methanol; MS, molecular sieves, MTT, (3-(4,5-Dimethylthiazol-2-yl)-2,5-diphenyltetrazolium bromide; MW, molecular weight; NMR, nuclear magnetic resonance spectroscopy; r.t., room temperature; TBDMS, tertbutyldimethylsilyl; THF, tetraydrofuran; TLC, thin layer chromatography. 



\section{Abstract}

Resveratrol (3,5,4'-trihydroxystilbene, RES) is a natural product reported to display relevant and varied biological activity. However, its low bioavailability and rapid metabolism to its glucuronate and sulfate conjugates has opened a debate on the mechanisms underlying its bioactivity. At the same time, resveratrol derivatives and prodrugs are being developed to circumvent these difficulties. We have synthesized a series of resveratrol prodrugs and resveratrol metabolites and evaluated their cytotoxicity, VEGF expression and telomerase inhibition. One healthy (human embryonic kidney, HEK-293) and two tumoral cell lines (human colon HT-29 and breast adenocarcinoma MCF-7) were used for the assays. Cytotoxic measurements revealed that resveratrol glucosylated prodrugs 2-4 and piceid octanoate 7 were more cytotoxic than resveratrol itself and more interestingly piceid $\mathbf{2}$, resveratrol-3,5diglucoside $\mathbf{3}$, and resveratrol-3,4'disulfate $\mathbf{1 0}$ combine relatively high cytotoxicity and high therapeutic safety margins. VEGF production in HT-29 cells was decreased by piceid $\mathbf{2}$ and resveratrol-3,4'disulfate $\mathbf{1 0}$ whereas resveratrol-3,5-diglucoside $\mathbf{3}$ and piceid octanoate $\mathbf{7}$ diminished it to a higher extent than resveratrol. Finally, $\mathbf{3}$ and $\mathbf{1 0}$ were also able to inhibit the expression of the hTERT gen that could be correlated to a lower transcription of the c-Myc gene for 3 but not for RES disulfate metabolite 10. In conclusion, resveratrol prodrugs such as resveratrol-3,5-diglucoside $\mathbf{3}$ could be promising candidates as anticancer drugs. In addition, RES sulphate metabolites have shown their own biological activity indicating they are not simply RES reservoirs. 


\section{INTRODUCTION}

Resveratrol (trans-3,5,4'-trihydroxystilbene, 1, see Figure 1) is a phytoalexin generated in response to environmental stress or pathogenic attack in grapes, blueberries, peanuts, cocoa and plants such as the Japanese knotweed Polygonum cuspidatum. Resveratrol has raised a great attention due to its relevant and varied biological activity such as its cardiovascular protective properties (1), antiinflammatory activity (2) or its capacity to extend lifespan in a variety of species (3). The cancer chemopreventive and chemotherapeutic potential of resveratrol has been demonstrated in different models of carcinogenesis in vitro and in vivo. It inhibits the proliferation of a variety of cancer cell lines (4) and in animal studies, resveratrol is able to interfere with the formation of azoxymethane$(\mathrm{AOM})$ induced aberrant crypt foci in rat colon (5), reduce mammary tumour formation in $\mathrm{N}$ methyl-N-nitrosourea-(NMU) treated rats (6) or suppress prostate cancer in SV-40 tag rats (7). In fact, extensive in vitro studies have revealed multiple intracellular targets of resveratrol, which affect cell growth, inflammation, apoptosis and metastasis (8).

Tumor angiogenesis also plays a critical role in the development of cancer. Resveratrol 1 and piceid (resveratrol-3- $\beta$-glucoside, 2 ) have shown to inhibit the formation of capillary-like tube formation from human umbilical vein endothelial cells (HUVEC) $(9,10)$. At the same time, vascular endothelial growth factor (VEGF) is crucial for angiogenesis and tumor growth, as it is involved in blood vessel development. In breast cancer cells, a significant decrease in extracellular levels of VEGF has been associated with apoptosis following resveratrol treatment (11). 

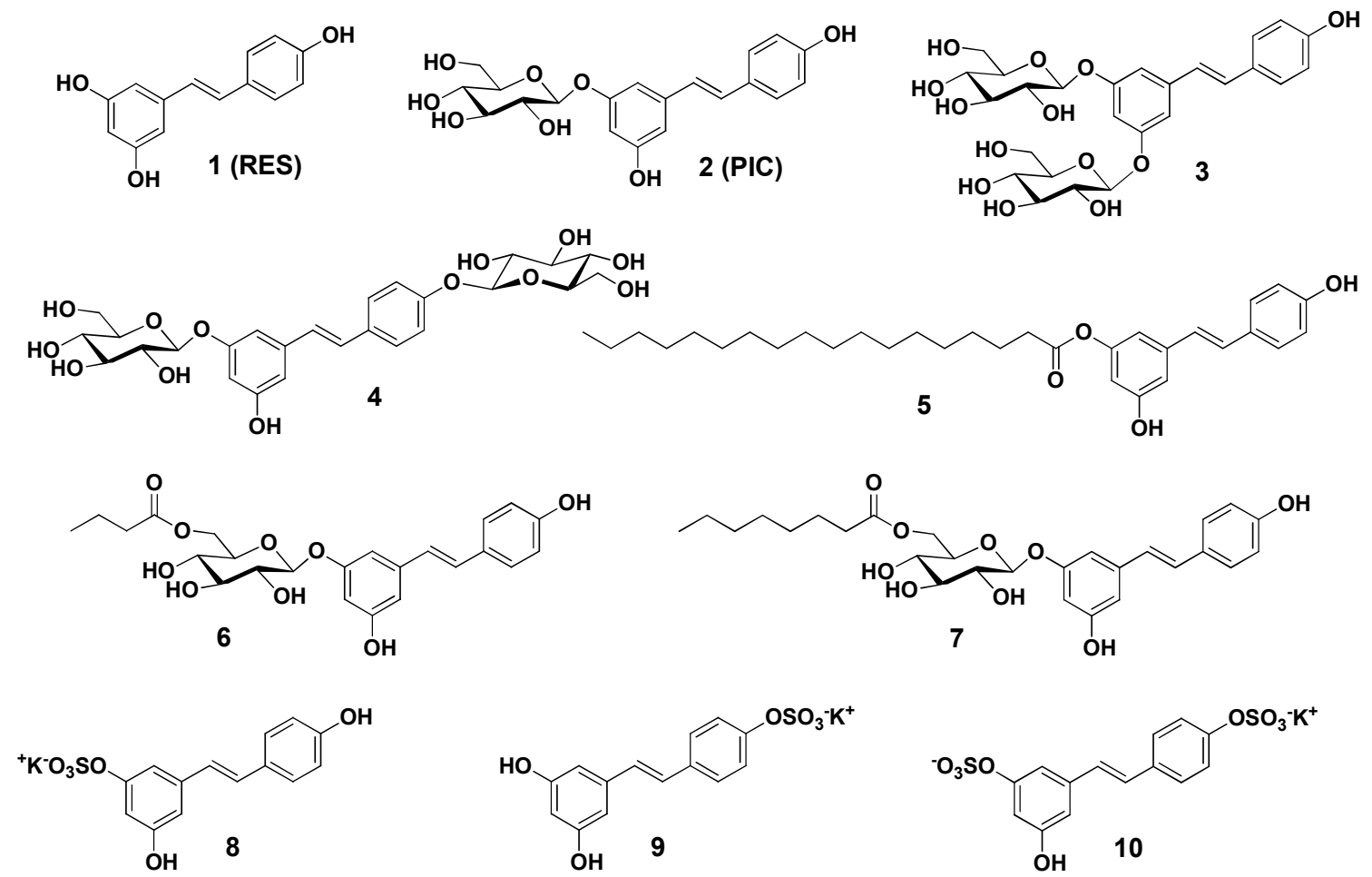

\section{Figure 1}

A relevant aspect observed in $90 \%$ of malignant tumors is the maintenance of the telomeres length within the cellular DNA through the expression of the telomerase reverse transcriptase (hTERT). This process allows cancer cells to elude the progressive shortening of the telomeres and finally avoid apoptosis. Resveratrol showed an inhibitory effect on MCF-7 tumor cell line mainly due to induce S-phase arrest and apoptosis in association with reduced expression of hTERT (12).

However, as is the case with many polyphenols with putative anticancer properties, the bioavailability of resveratrol is very low (13). Resveratrol is well absorbed but avidly glucuronidated and sulphated both in the liver and in intestinal epithelial cells (14-17). In order to counteract this effect, high doses of resveratrol have been used in cellular, animal and clinical studies. This could be the cause of toxicity observed in certain cases such as in a multiple myeloma study in humans where 5 grams a day of a formulation of resveratrol were administered. 
The low amounts of resveratrol observed systemically have brought the debate on the possible contribution of the resveratrol metabolites to the in vivo biological activities attributed to resveratrol $(13,18)$. It has been proposed that resveratrol metabolites could contribute as a resveratrol reservoir through their deconjugation or that resveratrol metabolites could enter the cell using $\mathrm{ABC}$ transporters and interact directly with different intracellular targets (19).

Moreover, resveratrol prodrugs are being investigated as an alternative trying to increase resveratrol bioavailability $(20-24)$. We had previously prepared a family of resveratrol prodrugs and pro-prodrugs attaching glucosyl- or acyl- groups to resveratrol $\mathbf{1}$ or piceid 2 and examined their anti-inflammatory effect on an inflammatory bowel disease (IBD) mice model (25). We observed that oral administration of trans-resveratrol-3-O-(6'-Obutanoyl)- $\beta$-D-glucopyranoside (6) and trans-resveratrol-3-O-(6'-O-octanoyl)- $\beta$-Dglucopyranoside (7) produced an increase delivery of resveratrol to the colon, prevented the rapid metabolism of resveratrol and reduced inflammation in a murine dextran sodium sulphate (DSS) model.

In the present study, we have measured cytotoxicity studies, VEGF expression and telomerase inhibition of five resveratrol prodrugs 3-7 modified with glucosyl- or acylgroups. The idea was to find out their potential as cancer chemopreventive or chemotherapeutic agents either if they act as such or as a resveratrol reservoir. In addition, we have synthesized three resveratrol sulphate metabolites 8-10 using an improved synthetic route. We have also tested their biological activity and compared it with resveratrol itself trying to shed some light on the controversy of resveratrol metabolites biological activity. 


\section{CHEMISTRY}

Diglucosylated resveratrol derivatives, trans-resveratrol-3,5-di- $O$ - $\beta$-Dglucopyranoside (3) and trans-resveratrol-3,5-di- $O$ - $\beta$-D-glucopyranoside (4) were synthesized from resveratrol (RES, 1) as described previously (25). Briefly, mono-TBDMS protected resveratrol compounds obtained by random silylation of RES were glycosylated using 2,3,4,6-tetra-O-benzoyl-D-glucopyranosyl trichloroacetimidate as the glycosyl donor. Final one step deprotection under aqueous strong basic conditions yielded the desired products 3 and 4 . Piceid acyl derivatives, trans-resveratrol-3-O-(6'-O-butanoyl)- $\beta$-Dglucopyranoside (6) and trans-resveratrol-3-O-(6'-O-octanoyl)- $\beta$-D-glucopyranoside (7), were synthesized by enzymatic acylation using Thermomyces lanuginosus lipase immobilized on granulated silica (Lipozyme TL IM) as reported earlier (25).

Resveratrol sulphate metabolites 8-10 were synthesized following the strategy reported by Hoshino et al.(26). First, TBDMS-protected resveratrol derivatives 11-15 were obtained from RES and each compound separated by flash column chromatography. However, posterior sulphation of each RES derivative using $\mathrm{SO}_{3} \cdot \mathrm{NMe}_{3}$ as sulphating reagent under acetonitrile reflux followed by silyl deprotection resulted in very low yields (10-26\%). Difficulties may come from no completion of the sulphation reaction and the difficult purification of these highly polar products. 
We have used instead microwave-assisted synthesis as reported by the group of Desai $(27,28)$ for highly sulphated organic scaffolds. TBDMS-protected resveratrol derivatives 1113 were treated with $\mathrm{SO}_{3} \cdot \mathrm{NMe}_{3}$ and $\mathrm{NEt}_{3}$ in acetonitrile and microwaves applied at $100{ }^{\circ} \mathrm{C}$ for 20-40 minutes (Scheme 1). The crude was purified using LH-20 chromatography and desilylation was carried out using $\mathrm{KF}$ in $\mathrm{MeOH}$ during $18 \mathrm{~h}$. Final crude purification was carried out using reversed-phase chromatography to obtain 8-10 in good yields (73-89\%).

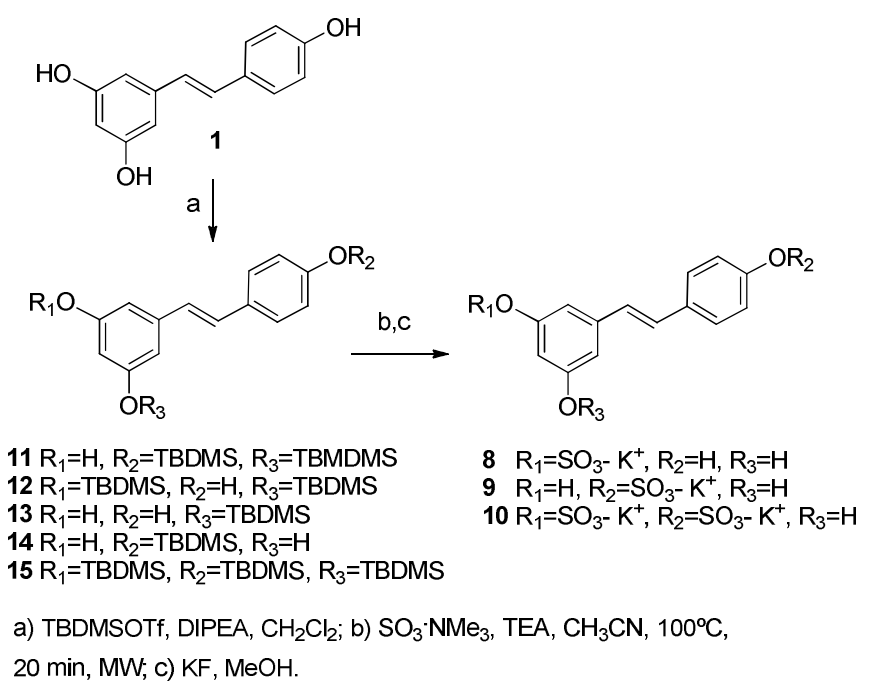

\section{Scheme 1}

\section{BIOLOGICAL RESULTS AND DISCUSSION}

In vitro cytotoxicity. The cytotoxicity of resveratrol derivatives 2-7 and resveratrol sulphate metabolites 8-10 was evaluated in vitro against two cancer cell lines, the human colon adenocarcinoma HT-29 and the breast adenocarcinoma MCF-7 cell lines. In addition, one normal cell line, the human embryonic kidney cell line (HEK-293) was employed in the assays for comparison (29). The standard MTT assay was used as described in the Experimental Section. Resveratrol 1 was used as the positive control. Cytotoxicity values, expressed as the compound concentration $(\mu \mathrm{M})$ that causes $50 \%$ inhibition of cell growth ( $\left.\mathrm{IC}_{50}\right)$, are shown in Table 1. The observed values are in most cases in the low to medium 
micromolar range. Among the resveratrol derivatives, glucosylated compounds (piceid 2, 3 and 4) and piceid octanoate 7 showed the highest cytotoxicities for the HT-29 cell line, with $\mathrm{IC}_{50}$ values lower than those of resveratrol. A similar trend is observed for the MCF-7 cell line where the lowest $\mathrm{IC}_{50}$ values were observed for piceid $\mathbf{2}$ and piceid octanoate $\mathbf{7}$.

Cytotoxic values have been reported for piceid $\mathbf{2}$ in several cancer cell lines with a wide range of $\mathrm{IC}_{50}$ values, being for example on MCF-7 cells from 1.5 to $300 \mu \mathrm{M}$ (30-32). When piceid is compared with resveratrol, $\mathrm{IC}_{50}$ values were in the same range or higher $(31$, 33). In our case, piceid $\mathrm{IC}_{50}$ values measured were in between those reported previously and in both cell lines (HT-29 and MCF-7) were lower than those obtained for resveratrol. The differences found in cytoxicity values for piceid may come from the different methodologies used to measure cell viability or from the different purity of piceid used in these studies.

It is important to remark that glucosyl resveratrol derivatives $\mathbf{2 - 4}$ tested are more toxic for tumoral cells than for normal ones, an obviously desirable feature. This can be better appreciated with the $\alpha$ and $\beta$ coefficients, obtained by dividing the $\mathrm{IC}_{50}$ values of the normal cell line (HEK-293) by those values of one or the other tumoral cell line (see footnote in Table 1). The higher value of the $\alpha$ or the $\beta$ coefficient, the higher is the therapeutic safety margin of the compound in the corresponding cell line. Thus, resveratrol is relatively cytotoxic for the normal cell line compared with cytotoxicity exhibited in both cancer cell lines. In contrast, piceid $\mathbf{2}$ and 3,5-diglucosyl-resveratrol $\mathbf{3}$ show a good selectivity in the case of the HT-29 line ( $\alpha>5.6$ and 4.2 and respectively). Zhang et al. (30) have also described that piceid $\mathbf{2}$ is more potent eliminating cancer cells than non-cancer cells for a variety of cell lines.

Storniolo et al. has reported recently that piceid 2 inhibited Caco-2 cell growth (1-50 $\mu \mathrm{M})$. Since the authors did not observed $\beta$-glucosidase activity they proposed that piceid presents antiproliferative effects on intestinal epithelial cells by itself and not as a resveratrol 
reservoir. This could also be the case in our assays for piceid $\mathbf{2}$ and the glycosylated RES derivatives 3 and 4 . However, we observed previously (25) that glucosyl- or acylmodifications in resveratrol prodrugs $2,3,4,6$ and 7 retarded their metabolism in Caco- 2 cells but were indeed metabolized to RES and its conjugates (glucuronates, sulfates, etc.) after 6-24h incubation times. Therefore, compounds $\mathbf{2 - 4}, \mathbf{6}$ and 7 seem to acting just as prodrugs delivering RES to the cells.

Table 1. Cytotoxicity of resveratrol and compounds $\mathbf{2 - 1 0}{ }^{[\mathrm{a}]}$

\begin{tabular}{|c|c|c|c|c|c|}
\hline & HT-29 & MCF-7 & HEK-293 & $\alpha^{[b]}$ & $\beta^{[\mathrm{c}]}$ \\
\hline RES (1) & $70 \pm 3$ & $127 \pm 22$ & $12 \pm 3.5$ & 0.2 & 0.1 \\
\hline 2 & $18 \pm 8$ & $38 \pm 18$ & $>100$ & $>5.6$ & $>2.6$ \\
\hline 3 & $24 \pm 0.5$ & $72 \pm 18$ & $>100$ & $>4.2$ & $>1.4$ \\
\hline 4 & $45 \pm 9$ & $89 \pm 16$ & $>100$ & $>2.2$ & $>1.1$ \\
\hline 5 & $99 \pm 24$ & $115 \pm 12$ & $>100$ & $>1.0$ & $>0.9$ \\
\hline 6 & $137 \pm 20$ & $110 \pm 7$ & $>100$ & $>0.7$ & $>0.9$ \\
\hline 7 & $39 \pm 2$ & $52 \pm 2$ & $15 \pm 4$ & 0.4 & 0.3 \\
\hline 8 & $115 \pm 17$ & $17 \pm 1$ & $>100$ & $>0.9$ & $>5.9$ \\
\hline 9 & $>100$ & $144 \pm 32$ & $>100$ & $>1.0$ & $>0.7$ \\
\hline 10 & $56 \pm 4$ & $26 \pm 4$ & $>100$ & $>1.8$ & $>3.8$ \\
\hline
\end{tabular}


When cytotoxicity was measured for the resveratrol sulphated metabolites 8-10, we found low $\mathrm{IC}_{50}$ values for resveratrol-3-sulphate $\mathbf{8}$ and resveratrol-3,4'-disulphate $\mathbf{1 0}$ on MCF-7 cells (17 and $26 \mu \mathrm{M}$, respectively). In fact, these two metabolites were more toxic than resveratrol itself $(127 \mu \mathrm{M})$. In the case of HT-29 cells, only resveratrol-3,4'-disulphate 10 was slightly more toxic than resveratrol. It is relevant to point out that sulphate resveratrol metabolites 8-10 had low toxicity on the normal cell line HEK-293, and it is especially interesting the high safety margin for $\mathbf{8}$ and $\mathbf{1 0}$ in the MCF-7 line $(\beta>5.9$ and 3.8, respectively).

Several reports have found low or no cytoxicity $(>100 \mu \mathrm{M})$ of resveratrol sulphated metabolites in a variety of cancer cells (MDA-MB-231, ZR-55-1, KB and neuroblastoma cells) $(26,34,35)$. In contrast, more recent studies have described higher cytoxicity for resveratrol-3-sulphate 8 (11-35 $\mu \mathrm{M})$ in different cancer cell lines (Caco-2, CCL-228, HCT116, SW620 and SW480) (36-38). In the same three studies, resveratrol 3-O-D-glucuronide and resveratrol 4'-O-D-glucuronide, another common resveratrol metabolites, also resulted cytotoxic (10-35 $\mu \mathrm{M})$, except on SW620 and SW480 cell lines. In the specific case of MCF-7 cells, Hoshino et al. (26) reported $\mathrm{IC}_{50}$ values $>50 \mu \mathrm{M}$ for resveratrol-3-sulphate 8. We obtained slightly higher toxicity for compound $\mathbf{8}$, showing similar values than the corresponding resveratrol-3,4'-disulphate 10. Polycarpou et al. (38) suggested that the differences reported on cytoxicity for the resveratrol metabolites could be due to the use of different assays to measure cell viability.

Resveratrol sulfate metabolites have been suggested to provide an intracellular pool for resveratrol generation (39). Our results show that sulfate resveratrol metabolites are equally or more active as antiproliferative agents that RES itself pointing out they probably contribute to the in vivo biological activity observed for resveratrol. 
Effect of resveratrol derivatives and sulfate metabolites on VEGF production. One of the key factors in the angiogenesis process is the release of VEGF from cancer cells. We decided to examine whether our resveratrol derivatives and metabolites were able to inhibit or at least decrease the activation of VEGF genes in HT-29 tumoral cells. We selected for this study glucosylated resveratrol compounds $\mathbf{2}$ and $\mathbf{3}$, piceid octanoate $\mathbf{7}$, and resveratrol sulphate metabolites 8, 9 and 10. Again, resveratrol 1 was used as the positive control. We determined VEGF protein production by ELISA in culture supernatants. Figure 1 shows the results obtained in ELISA measurements after treatment of HT-29 cells with resveratrol derivatives in DMSO. Piceid 2, 3,5-diglucosyl-resveratrol 3, piceid octanoate 7, and resveratrol 3,4'-disulphate $\mathbf{1 0}$ decreased VEGF secretion in HT-29 cells in comparison with untreated cells. In fact, compounds $\mathbf{3}$ and $\mathbf{7}$ are more effective than resveratrol $\mathbf{1}$ itself.

Piceid 2 had been shown previously to inhibit angiogenesis on human umbilical vein endothelial cells at concentrations of 100 to $1000 \mu \mathrm{M}$ what is in accordance to our experiments. Two permethylated stilbene derivatives (40-42) and a family of resveratrol dimers (43) have also been reported to inhibit VEGF production. In the case of the sulfate resveratrol derivatives, it is surprising that resveratrol 3,4'-disulphate 10 reduces VEGF secretion whereas the monosulfates $\mathbf{8}$ and $\mathbf{9}$ do not. In this scenario, it is difficult to imagine that resveratrol 3,4'-disulphate $\mathbf{1 0}$ could be a resveratrol reservoir since neither resveratrol-3sulfate 8 or resveratrol-4'-sulfate 9 display antiangiogenic activity. 


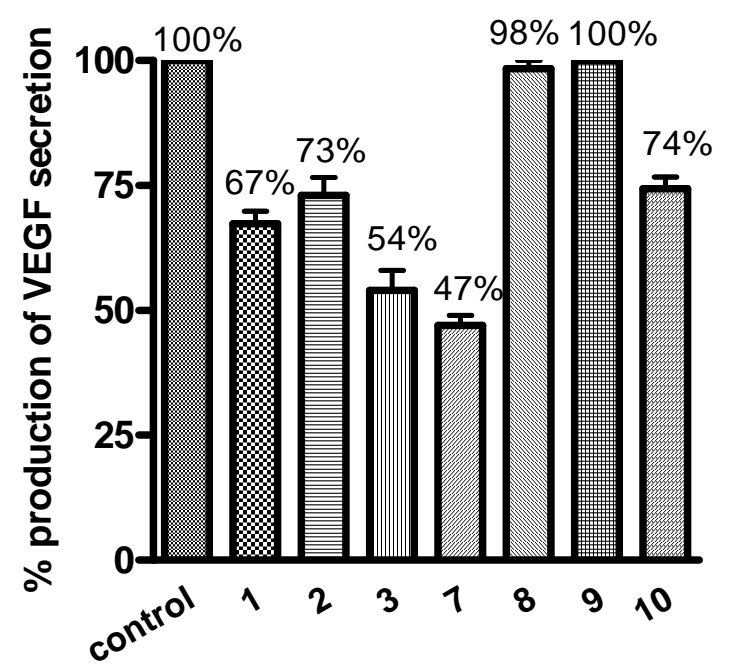

Figure 1. Percentage of production of VEGF from HT-29 cells treated with DMSO, resveratrol 1, piceid 2, 3, 7, 8, 9 and $\mathbf{1 0}$ (conc. $20 \mu \mathrm{g} / \mathrm{mL}$ for $\mathbf{1}$ and $10 \mu \mathrm{g} / \mathrm{mL}$ for the rest of compounds) related to not treated cells. At least three measurements were performed in each case. Bars shown represent mean values of VEGF expression percentage related to control. Error bars indicate standard errors of the mean. Statistical significance was evaluated using one-sample t-tests $(\mathrm{P}<0.001)$.

Effect of resveratrol derivatives on telomerase production. Human telomerase contains an RNA component (hTER) that serves as a template for the addition of the repeat nucleotide sequences and a protein subunit (hTERT) which catalyzes the nucleotide polymerization process. Human telomerase is regulated during development and differentiation, mainly through transcriptional control of the hTERT gene, the expression of which is restricted to cells that exhibit telomerase activity. This indicates that hTERT is the rate limiting factor of the enzyme complex (44). Transcriptional factors c-Myc and Sp1 are, among others, implicated in the expression of the hTERT gene. These factors upregulate mRNA encoding the hTERT protein subunit of telomerase (45-47). Thus, and as a preliminary study of the potential anti-telomerase activity of resveratrol derivatives, we have 
investigated their ability to inhibit the expression of the hTERT and c-Myc genes. For that purpose, we selected the same group of resveratrol derivatives (2, 3 and 7) and metabolites $(\mathbf{8}, \mathbf{9}$ and 10) as previously investigated for their VEGF inhibition activity. Resveratrol $\mathbf{1}$ was used again as control.

The results are depicted in figures 2 and 3 and show that treatment of HT-29 cells with resveratrol and the aforementioned derivatives leads in fact to various degrees of reduction in the transcription of hTERT and c-Myc mRNA as compared with control cells. The most active compounds as regards to inhibition of hTERT expression are 3,5diglucosylated resveratrol $\mathbf{3}$ and resveratrol-3,4'-disulphate $\mathbf{1 0}$ which showed higher inhibition of hTERT gene expression than resveratrol itself. Particularly appealing is resveratrol metabolite $\mathbf{1 0}$ which was able to reduce the expression of this gene to $39 \%$ of the control value. For the sake of comparison, resveratrol 1 caused a reduction to $61 \%$ of the control value in the case of the hTERT gene.

Regarding c-Myc inhibition our study revealed that resveratrol 1 and 3,5-diglucosylresveratrol 3 are the most active compounds (48\% and $66 \%$ respectively, see figure 3 ). Compounds 2, 8, 9 and 10 proved inactive in the inhibition of c-Myc gene expression. Resveratrol and compound $\mathbf{3}$ show some correlation between inhibition of c-Myc and hTERT gene expression (61\% and 52\%, see figure 2), indicating that resveratrol and compound 3 could downregulate the expression of the hTERT gene by lowering the transcription of the cMyc gene. In contrast, this is not the case for resveratrol metabolite $\mathbf{1 0}$ which showed the highest inhibition of hTERT on this series but does not downregulate c-Myc gene expression. A different mechanism seems to be used by metabolite $\mathbf{1 0}$ pointing out again the fact that resveratrol-3,4'-disulfate is not just a resveratrol reservoir but instead that this resveratrol metabolite displays its on biological responses. 


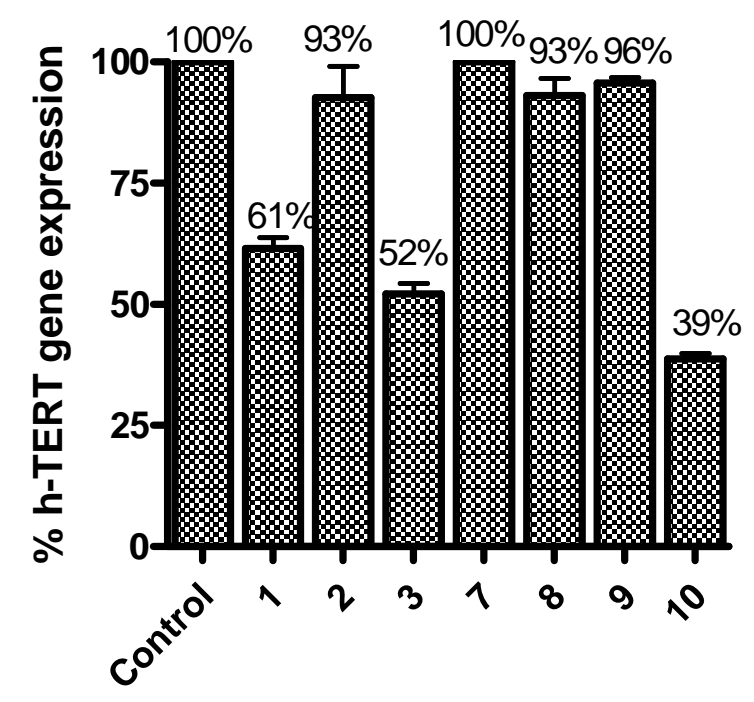

Figure 2. Gene expression of hTERT was normalized to that of the housekeeping gene $\beta$ actin. At least three measurements were performed in each case. Bars shown represent mean values of hTERT gene expression and error bars indicate standard errors of the mean. The statistical significance was evaluated using one-sample t-tests $(\mathrm{P}<0.001)$.

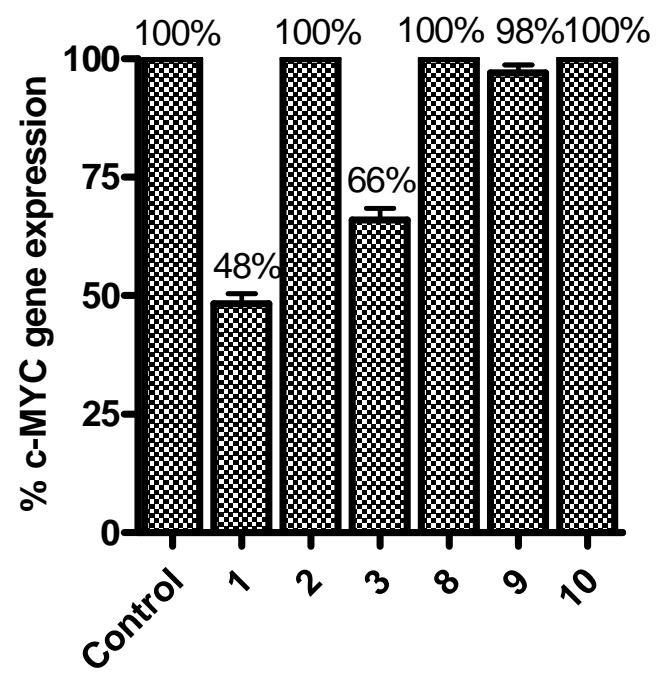

Figure 3. Gene expression of c-Myc was normalized to that of the housekeeping gene $\beta$-actin. At least three measurements were performed in each case. Bars shown represent mean values 
of c-Myc gene expression and error bars indicate standard errors of the mean. The statistical significance was evaluated using one-sample t-tests $(\mathrm{P}<0.001)$.

In conclusion, resveratrol derivatives $\mathbf{2}, \mathbf{3}, \mathbf{4}$ and $\mathbf{7}$ displayed higher antiproliferative and antiangiogenic activity than resveratrol itself and, at the same time, these compounds showed less toxicity in HEK-293 cells. Most probably these derivatives are acting as RES prodrugs, delivering more slowly resveratrol to the cancer cells and therefore, also delaying RES metabolism. In the case of resveratrol sulfate metabolites 8-10, we observed equal or higher cytotoxicity than resveratrol in HT-29 and MCF-7 cells together with lower toxicity in healthy human cells. The fact that that resveratrol disulfate $\mathbf{1 0}$ decreases VEGF secretion but no activity is observed for resveratrol monosulfates $\mathbf{8}$ and $\mathbf{9}$ seems to indicate an intrinsic activity of $\mathbf{1 0}$ more than just a resveratrol reservoir. Finally, resveratrol metabolite $\mathbf{1 0}$ seems to decrease hTERT expression via a different mechanism than resveratrol itself since $\mathbf{1 0}$ does not affect c-Myc formation. These results indicate that resveratrol metabolites contribute to the in vivo biological activity observed for resveratrol and not only act as a resveratrol reservoir.

\section{Acknowledgments}

Financial support has been granted by the Spanish Government (Ministerio de Economía y Competitividad, projects CTQ2011-27560 and CTQ2012-35360), by the Consellería d'Empresa, Universitat i Ciencia de la Generalitat Valenciana (projects PROMETEO/2013/027) and by the Universitat Jaume I (project PI-1B-2011-37). 


\section{Experimental Section}

\section{Chemistry: general procedures}

All chemicals obtained from commercial sources were used without further purification, unless otherwise noted. All reactions were monitored by TLC on precoated Silica-Gel 60 plates F254, and detected by heating with Mostain $\left(500 \mathrm{ml}\right.$ of $10 \% \mathrm{H}_{2} \mathrm{SO}_{4}, 25 \mathrm{~g}$ of $\left.\left(\mathrm{NH}_{4}\right)_{6} \mathrm{Mo}_{7} \mathrm{O}_{24} \bullet 4 \mathrm{H}_{2} \mathrm{O}, 1 \mathrm{~g} \mathrm{Ce}\left(\mathrm{SO}_{4}\right)_{2} \bullet 4 \mathrm{H} 2 \mathrm{O}\right)$. Products were purified by flash chromatography with Merck Silica gel 60 (200-400 mesh). Mass spectra analyses were run in the electrospray mode (ESIMS). NMR spectra were recorded on 300 or $400 \mathrm{MHz}$ spectrometers, at room temperature for solutions in $\mathrm{CDCl}_{3}$ or $\mathrm{D}_{2} \mathrm{O}$. Chemical shifts are referred to the solvent signal. Metabolites were purified by Sephadex LH-20 and RP-C18 chromatography.

\section{Reaction Conditions}

\section{Glucosylated resveratrol derivatives}

Resveratrol (1, RES) and piceid (trans-resveratrol-3-O- $\beta$-D-glucopyranoside, 2, PIC) are commercially available. Diglucosylated resveratrol derivatives $\mathbf{3}$ and $\mathbf{4}$ were prepared as reported previously (25).

\section{Acylated resveratrol derivatives}

3-O-stearoyl-trans-resveratrol (5) was kindly provided by Dr. F. J. Plou. Briefly, preparation of 5 involves enzymatic acylation from RES using immobilized lipase from Alcaligenes sp. (lipase QLG) as reported previously (48). Piceid acyl derivatives (6-7) were also synthesized by enzymatic acylation as described earlier by our group (25).

\section{Resveratrol sulphate metabolites}

\section{General procedure for the microwave-assisted O-sulfonation and desylilation:}

Microwave based sulfonation reactions were performed using a microwave synthesizer in sealed reaction vessels. Sulfur trioxide-trimethylamine complex was previously washed with $\mathrm{H}_{2} \mathrm{O}, \mathrm{MeOH}$, and $\mathrm{CH}_{2} \mathrm{Cl}_{2}$ and dried under high vacuum. TBDMS-protected resveratrol 
derivative (1.0 equiv), sulfur trioxide-trimethylamine complex (5 equiv per $\mathrm{OH}$ ) and a magnetic stirrer bar were placed in a $2-5 \mathrm{~mL}$ microwave reaction vial and fitted with a septum, which was then pierced with a needle. The closed vial was then evacuated under high vacuum for $2 \mathrm{~h}$. The mixture was dissolved in dry $\mathrm{CH}_{3} \mathrm{CN}(2.0 \mathrm{~mL})$ and $\mathrm{NEt}_{3}(0.3-1.0 \mathrm{~mL})$ was then added. Reaction mixture was subjected to microwave radiation for $20-40 \mathrm{~min}$ at $100{ }^{\circ} \mathrm{C}\left(50-60 \mathrm{~W}\right.$ average power). $\mathrm{MeOH}(1 \mathrm{~mL})$ and $\mathrm{CH}_{2} \mathrm{Cl}_{2}(1 \mathrm{~mL})$ were added, and the solution was layered on the top of a Sephadex LH-20 chromatography column which was eluted with $\mathrm{CH}_{2} \mathrm{Cl}_{2} / \mathrm{MeOH}$ (1:1) to obtain the corresponding triethylammonium salt. The product and $\mathrm{KF}$ (2.0 equiv) were dissolved in $\mathrm{MeOH}(5 \mathrm{~mL})$. The reaction mixture was stirred at room temperature for $18 \mathrm{~h}$ and the solvent was then removed under vacuum. The crude was purified by RP-C18 eluting with $\mathrm{H}_{2} \mathrm{O}: \mathrm{CH}_{3} \mathrm{OH}$ from 100:0 to 70:30). Fractions containing the desired product were concentrated and freeze-dried affording the corresponding resveratrol sulphated compounds. Yields were: $8(73 \%), 9(82 \%)$ and 10 $(93 \%)$

\section{Biological procedures}

\section{Cell culture}

Cell culture media were purchased from Gibco (Grand Island, NY, USA). Fetal bovine serum (FBS) was a product of Harlan-Seralab (Belton, U.K.). Supplements and other chemicals not listed in this section were obtained from Sigma Chemicals Co. (St. Louis, Mo., USA). Plastics for cell culture were supplied by Thermo Scientific ${ }^{\mathrm{TM}}$ BioLite. All tested compounds were dissolved in DMSO at a concentration of $10 \mu \mathrm{g} / \mathrm{mL}$ and stored at $-20^{\circ} \mathrm{C}$ until use. 
Cell lines were maintained in Dulbecco's modified Eagle's medium (DMEM) containing glucose $(1 \mathrm{~g} / \mathrm{L})$, glutamine $(2 \mathrm{mM})$, penicillin $(50 \mathrm{IU} / \mathrm{mL})$, streptomycin $(50 \mu \mathrm{g} / \mathrm{mL})$ and amphoterycin $(1.25 \mu \mathrm{g} / \mathrm{mL})$, supplemented with $10 \%$ FBS.

\section{Cytotoxicity assays}

The 3-(4,5-dimethylthiazol-2-yl)-2,5-diphenyltetrazolium bromide (MTT; Sigma Chemical Co., St. Louis, MO) dye reduction assay in 96-well microplates was used, as previously described (49). Some $5 \times 10^{3}$ cells of HT-29, MCF-7 or HEK-293 cells in a total volume of $100 \mu \mathrm{L}$ of their respective growth media were incubated with serial dilutions of the tested compounds. After 3 days of incubation $\left(37^{\circ} \mathrm{C}, 5 \% \mathrm{CO}_{2}\right.$ in a humid atmosphere), $10 \mu \mathrm{l}$ of MTT $(5 \mathrm{mg} / \mathrm{ml}$ in PBS) were added to each well and the plate was incubated for further $4 \mathrm{~h}$ $\left(37^{\circ} \mathrm{C}\right.$ ). The resulting formazan was dissolved in $150 \mu \mathrm{L}$ of $0.04 \mathrm{~N} \mathrm{HCl} / 2$-propanol and read at $550 \mathrm{~nm}$. All determinations were carried out in triplicate.

\section{ELISA analysis}

HT-29 cells at 70-80\% confluence were collected after serum starvation for $24 \mathrm{~h}$. Cells were incubated with $20 \mu \mathrm{g} / \mathrm{mL}$ resveratrol in DMSO and with $10 \mu \mathrm{g} / \mathrm{mL}$ of the corresponding stilbene in DMSO for $72 \mathrm{~h}$. Culture supernatants were collected and VEGF secreted by HT29 cells was determined using Invitrogen Human Vascular Endothelial Growth Factor ELISA Kit according to the manufacturer's instructions.

\section{RT-qPCR analysis}

HT-29 cells at 70-80\% confluence were collected after serum starvation for $24 \mathrm{~h}$. Cells were incubated with combretastatin derivatives in DMSO (see Figs. 2 and 3) for 48 h. Cells were collected and the total cellular RNA from HT-29 cells was isolated using Ambion RNA extraction Kit according to the manufacturer's instructions. The cDNA was synthesized by 
MMLV-RT with 1-21 $\mu \mathrm{g}$ of extracted RNA and oligo(dT)15 according to the manufacturer's instructions.

Genes were amplified by use of a thermal cycler and StepOnePlus TM Taqman $®$ probes. TaqMan ${ }^{\circledR}$ Gene Expression Master Mix Fast containing the appropriate buffer for the amplification conditions, dNTPs, thermostable DNA polymerase enzyme and a passive reference probe was used. To amplify each of the genes the predesigned primers were used and sold by Life Technologies TaqMan ® Gene Expression Assays, Hs99999903-m1 ( $\beta$ actin), Hs00900055-m1 (VEGF), Hs00972646-m1 (hTERT) y Hs00153408-m1 (c-MYC).

\section{Literature}

1. Frankel, E. N.; Waterhouse, A. L.; Kinsella, J. E., Inhibition of human LDL oxidation by resveratrol. The Lancet 1993, 341, 1103-1104.

2. Jang, M.; Cai, L.; Udeani, G. O.; Slowing, K. V.; Thomas, C. F.; Beecher, C. W.; Fong, H. H.; Farnsworth, N. R.; Kinghorn, A. D.; Mehta, R. G.; Moon, R. C.; Pezzuto, J. M., Cancer chemopreventive activity of resveratrol, a natural product derived from grapes. Science 1997, 275, 218-20.

3. Allard, J. S.; Perez, E.; Zou, S.; de Cabo, R., Dietary activators of Sirt1. Mol Cell Endocrinol 2009, 299, 58-63.

4. Gusman, J.; Malonne, H.; Atassi, G., A reappraisal of the potential chemopreventive and chemotherapeutic properties of resveratrol. Carcinogenesis 2001, 22, 1111-7.

5. Tessitore, L.; Davit, A.; Sarotto, I.; Caderni, G., Resveratrol depresses the growth of colorectal aberrant crypt foci by affecting bax and p21(CIP) expression. Carcinogenesis 2000, 21, 1619-22.

6. Bhat, K. P.; Lantvit, D.; Christov, K.; Mehta, R. G.; Moon, R. C.; Pezzuto, J. M., Estrogenic and antiestrogenic properties of resveratrol in mammary tumor models. Cancer Res 2001, 61, 7456-63.

7. Harper, C. E.; Cook, L. M.; Patel, B. B.; Wang, J.; Eltoum, I. A.; Arabshahi, A.; Shirai, T.; Lamartiniere, C. A., Genistein and resveratrol, alone and in combination, suppress prostate cancer in SV-40 tag rats. The Prostate 2009, 69, 1668-1682.

8. Athar, M.; Back, J.-H.; Kopelovich, L.; Bickers, d. R.; Kim, A. L., Multiple molecular Targets of Resveratrol: Anti-carcinogenic Mechanisms. Arch Biochem Biophys 2009, 486, 95-102.

9. Kimura, Y.; Okuda, H., Effects of naturally occurring stilbene glucosides from medicinal plants and wine, on tumour growth and lung metastasis in Lewis lung carcinoma-bearing mice. J. Pharm. Pharmacol. 2000, 52, 1287-1295.

10. Kimura, Y.; Okuda, H., Resveratrol Isolated from Polygonum cuspidatum Root Prevents Tumor Growth and Metastasis to Lung and Tumor-Induced Neovascularization in Lewis Lung Carcinoma-Bearing Mice. J Nutr 2001, 131, 1844-1849.

11. Garvin, S.; Öllinger, K.; Dabrosin, C., Resveratrol induces apoptosis and inhibits angiogenesis in human breast cancer xenografts in vivo. Cancer Lett. 2006, 231, 113-122. 
12. Lanzilli, G.; Fuggetta, M. P.; Tricarico, M.; Cottarelli, A.; Serafino, A.; Falchetti, R.; Ravagnan, G.; Turriziani, M.; Adamo, R.; Franzese, O.; Bonmassar, E., Resveratrol down-regulates the growth and telomerase activity of breast cancer cells in vitro. Int $J$ Oncol 2006, 28, 641-8.

13. Cottart, C. H.; Nivet-Antoine, V.; Laguillier-Morizot, C.; Beaudeux, J. L., Resveratrol bioavailability and toxicity in humans. Mol Nutr Food Res 2010, 54, 7-16.

14. Marier, J. F.; Vachon, P.; Gritsas, A.; Zhang, J.; Moreau, J. P.; Ducharme, M. P., Metabolism and disposition of resveratrol in rats: extent of absorption, glucuronidation, and enterohepatic recirculation evidenced by a linked-rat model. J Pharmacol Exp Ther 2002, 302, 369-73.

15. Walle, T.; Hsieh, F.; DeLegge, M. H.; Oatis, J. E., Jr.; Walle, U. K., High absorption but very low bioavailability of oral resveratrol in humans. Drug Metab Dispos 2004, 32, 1377-82.

16. Burkon, A.; Somoza, V., Quantification of free and protein-bound trans-resveratrol metabolites and identification of trans-resveratrol-C/O-conjugated diglucuronides - Two novel resveratrol metabolites in human plasma. Mol. Nutr. Food Res. 2008, 52, 549-557.

17. Wenzel, E.; Somoza, V., Metabolism and bioavailability of trans-resveratrol. Mol Nutr Food Res 2005, 49, 472-81.

18. Baur, J. A.; Sinclair, D. A., Therapeutic potential of resveratrol: the in vivo evidence. Nat Rev Drug Discov 2006, 5, 493-506.

19. Maier-Salamon, A.; Bohmdorfer, M.; Riha, J.; Thalhammer, T.; Szekeres, T.; Jaeger, W., Interplay between metabolism and transport of resveratrol. Ann N Y Acad Sci 2013, 1290, 98-106.

20. Biasutto, L.; Marotta, E.; Bradaschia, A.; Fallica, M.; Mattarei, A.; Garbisa, S.; Zoratti, M.; Paradisi, C., Soluble polyphenols: synthesis and bioavailability of 3,4',5-tri(alpha-D-glucose-3-Osuccinyl) resveratrol. Bioorg Med Chem Lett 2009, 19, 6721-4.

21. Mattarei, A.; Azzolini, M.; Carraro, M.; Sassi, N.; Zoratti, M.; Paradisi, C.; Biasutto, L., Acetal derivatives as prodrugs of resveratrol. Mol Pharm 2013, 10, 2781-92.

22. Ma, L.; Zhao, Y.; Li, B.; Wang, Q.; Liu, X.; Chen, X.; Nan, Y.; Liang, L.; Chang, R.; Li, P.; Jin, F., 3,5,4'-Tri-O-acetylresveratrol attenuates seawater aspiration-induced lung injury by inhibiting activation of nuclear factor-kappa B and hypoxia-inducible factor-1alpha. Respir Physiol Neurobiol 2013, 185, 608-14.

23. Madrona, A.; Pereira-Caro, G.; Mateos, R.; Rodriguez, G.; Trujillo, M.; Fernandez-Bolanos, J.; Espartero, J. L., Synthesis of hydroxytyrosyl alkyl ethers from olive oil waste waters. Molecules 2009, $14,1762-72$.

24. Biasutto, L.; Zoratti, M., Prodrugs of quercetin and resveratrol: a strategy under development. Curr Drug Metab 2014, 15, 77-95.

25. Larrosa, M.; Tome-Carneiro, J.; Yanez-Gascon, M. J.; Alcantara, D.; Selma, M. V.; Beltran, D.; Garcia-Conesa, M. T.; Urban, C.; Lucas, R.; Tomas-Barberan, F.; Morales, J. C.; Espin, J. C., Preventive oral treatment with resveratrol pro-prodrugs drastically reduce colon inflammation in rodents. $J$ Med Chem 2010, 53, 7365-76.

26. Hoshino, J.; Park, E. J.; Kondratyuk, T. P.; Marler, L.; Pezzuto, J. M.; van Breemen, R. B.; Mo, S.; Li, Y.; Cushman, M., Selective synthesis and biological evaluation of sulfate-conjugated resveratrol metabolites. J Med Chem 2010, 53, 5033-43.

27. Raghuraman, A.; Riaz, M.; Hindle, M.; Desai, U. R., Rapid and efficient microwave-assisted synthesis of highly sulfated organic scaffolds. Tetrahedron Lett. 2007, 48, 6754-6758.

28. Al-Horani, R. A.; Desai, U. R., Chemical sulfation of small moleculesâ€"advances and challenges. Tetrahedron 2010, 66, 2907-2918.

29. Arden, N.; Betenbaugh, M. J., Life and death in mammalian cell culture: strategies for apoptosis inhibition. Trends Biotechnol 2004, 22, 174-80.

30. Zhang, Y.; Zhuang, Z.; Meng, Q.; Jiao, Y.; Xu, J.; Fan, S., Polydatin inhibits growth of lung cancer cells by inducing apoptosis and causing cell cycle arrest. Oncol Lett 2014, 7, 295-301.

31. Su, D.; Cheng, Y.; Liu, M.; Liu, D.; Cui, H.; Zhang, B.; Zhou, S.; Yang, T.; Mei, Q., Comparision of piceid and resveratrol in antioxidation and antiproliferation activities in vitro. PLoS One 2013, 8, e54505. 
32. Liu, H.; Zhao, S.; Zhang, Y.; Wu, J.; Peng, H.; Fan, J.; Liao, J., Reactive oxygen speciesmediated endoplasmic reticulum stress and mitochondrial dysfunction contribute to polydatininduced apoptosis in human nasopharyngeal carcinoma CNE cells. J Cell Biochem 2011, 112, 3695703.

33. Ha do, T.; Chen, Q. C.; Hung, T. M.; Youn, U. J.; Ngoc, T. M.; Thuong, P. T.; Kim, H. J.; Seong, Y. H.; Min, B. S.; Bae, K., Stilbenes and oligostilbenes from leaf and stem of Vitis amurensis and their cytotoxic activity. Arch Pharm Res 2009, 32, 177-83.

34. Miksits, M.; Wlcek, K.; Svoboda, M.; Kunert, O.; Haslinger, E.; Thalhammer, T.; Szekeres, T.; Jager, W., Antitumor activity of resveratrol and its sulfated metabolites against human breast cancer cells. Planta Med 2009, 75, 1227-30.

35. Kenealey, J. D.; Subramanian, L.; Van Ginkel, P. R.; Darjatmoko, S.; Lindstrom, M. J.; Somoza, V.; Ghosh, S. K.; Song, Z.; Hsung, R. P.; Kwon, G. S.; Eliceiri, K. W.; Albert, D. M.; Polans, A. S., Resveratrol metabolites do not elicit early pro-apoptotic mechanisms in neuroblastoma cells. J Agric Food Chem 2011, 59, 4979-86.

36. Storniolo, C. E.; Moreno, J. J., Resveratrol metabolites have an antiproliferative effect on intestinal epithelial cancer cells. Food Chemistry 2012, 134, 1385-1391.

37. Aires, V.; Limagne, E.; Cotte, A. K.; Latruffe, N.; Ghiringhelli, F.; Delmas, D., Resveratrol metabolites inhibit human metastatic colon cancer cells progression and synergize with chemotherapeutic drugs to induce cell death. Mol Nutr Food Res 2013, 57, 1170-81.

38. Polycarpou, E.; Meira, L. B.; Carrington, S.; Tyrrell, E.; Modjtahedi, H.; Carew, M. A., Resveratrol 3-O-D-glucuronide and resveratrol 4'-O-D-glucuronide inhibit colon cancer cell growth: evidence for a role of $\mathrm{A} 3$ adenosine receptors, cyclin D1 depletion, and G1 cell cycle arrest. Mol Nutr Food Res 2013, 57, 1708-17.

39. Patel, K. R.; Andreadi, C.; Britton, R. G.; Horner-Glister, E.; Karmokar, A.; Sale, S.; Brown, V. A.; Brenner, D. E.; Singh, R.; Steward, W. P.; Gescher, A. J.; Brown, K., Sulfate metabolites provide an intracellular pool for resveratrol generation and induce autophagy with senescence. Sci Transl Med 2013, 5, 205 ra133.

40. Belleri, M.; Ribatti, D.; Nicoli, S.; Cotelli, F.; Forti, L.; Vannini, V.; Stivala, L. A.; Presta, M., Antiangiogenic and vascular-targeting activity of the microtubule-destabilizing trans-resveratrol derivative 3,5,4'-trimethoxystilbene. Mol Pharmacol 2005, 67, 1451-9.

41. Alex, D.; Leong, E. C.; Zhang, Z. J.; Yan, G. T.; Cheng, S. H.; Leong, C. W.; Li, Z. H.; Lam, K. H.; Chan, S. W.; Lee, S. M., Resveratrol derivative, trans-3,5,4'-trimethoxystilbene, exerts antiangiogenic and vascular-disrupting effects in zebrafish through the downregulation of VEGFR2 and cell-cycle modulation. J Cell Biochem 2010, 109, 339-46.

42. Zhang, L.; Jing, H.; Cui, L.; Li, H.; Zhou, B.; Zhou, G.; Dai, F., 3,4-Dimethoxystilbene, a resveratrol derivative with anti-angiogenic effect, induces both macroautophagy and apoptosis in endothelial cells. J Cell Biochem 2013, 114, 697-707.

43. Kunimasa, K.; Ohta, T.; Tani, H.; Kato, E.; Eguchi, R.; Kaji, K.; Ikeda, K.; Mori, H.; Mori, M.; Tatefuji, T.; Yamori, Y., Resveratrol derivative-rich melinjo (Gnetum gnemon L.) seed extract suppresses multiple angiogenesis-related endothelial cell functions and tumor angiogenesis. $\mathrm{Mol}$ Nutr Food Res 2011, 55, 1730-4.

44. Olaussen, K. A.; Dubrana, K.; Domont, J.; Spano, J. P.; Sabatier, L.; Soria, J. C., Telomeres and telomerase as targets for anticancer drug development. Crit Rev Oncol Hematol 2006, 57, 191-214.

45. Dwyer, J.; Li, H.; Xu, D.; Liu, J. P., Transcriptional regulation of telomerase activity: roles of the the Ets transcription factor family. Ann N Y Acad Sci 2007, 1114, 36-47.

46. Kyo, S.; Takakura, M.; Fujiwara, T.; Inoue, M., Understanding and exploiting hTERT promoter regulation for diagnosis and treatment of human cancers. Cancer Sci 2008, 99, 1528-38.

47. Daniel, M.; Peek, G. W.; Tollefsbol, T. O., Regulation of the human catalytic subunit of telomerase (hTERT). Gene 2012, 498, 135-46. 
48. Torres, P.; Poveda, A.; Jimenez-Barbero, J.; Ballesteros, A.; Plou, F. J., Regioselective lipasecatalyzed synthesis of 3-O-acyl derivatives of resveratrol and study of their antioxidant properties. $J$ Agric Food Chem 2010, 58, 807-13.

49. Rodriguez-Nieto, S.; Medina, M. A.; Quesada, A. R., A re-evaluation of fumagillin selectivity towards endothelial cells. Anticancer Res 2001, 21, 3457-60. 